\title{
Protein $C$ activation in NIDDM patients
}

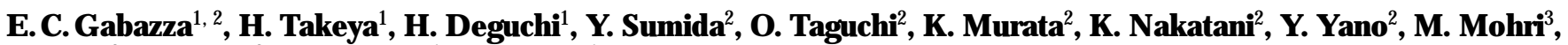 \\ M. Sata ${ }^{3}$, T. Shima ${ }^{2}$, J. N ishioka ${ }^{1}$, K. Suzuki ${ }^{1}$ \\ ${ }^{1} \mathrm{D}$ epartment of M olecular Pathobiology, M ie U niversity School of M edicine, M ie-ken, Japan \\ ${ }^{2}$ Third D epartment of I nternal M edicine, M ie U niversity School of M edicine, M ie-ken, Japan \\ ${ }^{3}$ A sahi Chemical I ndustry Company, Shizuoka, Japan
}

Summary E nhanced activation of the clotting system has been recently implicated in the pathogenesis of vascular complications in patients with diabetes mellitus. A bnormalities of the anticoagulant system may constitute a potential trigger factor for the haemostatic activation observed in diabetic subjects. The current study aimed to evaluate anticoagulant activity in diabetic patients by assessing the plasma levels of activated protein C-protein C inhibitor complex; and by measuring the anticoagulant response to exogenous thrombomodulin. This study comprised 61 patients (34 men, 27 women) with non-insulin-dependent diabetes mellitus (NID D M ) of whom 22 showed microalbuminuria and 39 normoalbuminuria. D ata obtained in 31 non-obese and non-diabetic subjects were available for comparison. The plasma levels of fibrinogen $(p<0.02)$, prothrombin fragment $1+2$ $(p<0.05)$, fibrin monomer $(p<0.0001)$, protein $C$ antigen $(p<0.005)$, total protein $S$ antigen $(p<0.02)$, soluble thrombomodulin $(p<0.005)$ and soluble $E$ selectin $(p<0.005)$ were significantly higher in diabetic patients than in healthy subjects. The plasma level of activated protein C-protein $C$ inhibitor complex $(7.4 \pm 3.8$ vs $3.0 \pm 0.4 \mathrm{pmol} / \mathrm{l})$ was significantly higher $(p<0.0001)$ and the anticoagulant response to exogenous thrombomodulin $(23.4 \pm 2.6$ vs $35.3 \pm$ $3.0 \mathrm{ng} / \mathrm{ml})$ was markedly lower $(p=0.005)$ in all diabetic patients than in healthy subjects. Cases with microalbuminuria presented low plasma levels of activated protein $C$-protein $C$ inhibitor complex (5.5 \pm 0.6 vs $8.6 \pm 0.7 \mathrm{pmol} / \mathrm{l}, \mathrm{p}<0.05)$ and significantly decreased values of the anticoagulant response to exogenous thrombomodulin ( $16.5 \pm 2.9$ vs $23.4 \pm 2.6 \%$, $p=0.03$ ) as compared to those with normoalbuminuria. The present study suggests that the hyper-coagulable state in NID D M is associated with an increased activation of protein $C$ but with a poor plasma reactivity to the anticoagulant effect of thrombomodulin. [D iabetologia (1996) 39: 1455-1461]

Keywords Protein C, protein S, diabetes mellitus, soluble thrombomodulin, microalbuminuria, activated protein C-protein $\mathrm{C}$ inhibitor complex, fibrin monomer, soluble E-selectin.
R eceived: 27 February 1996 and in revised form: 3 J une 1996

Corresponding author: K.Suzuki, Ph.D., D epartment of M olecular Pathobiology, M ie U niversity School of M edicine, 514 E dobashi 2-174, T su-city, M ie-ken, Japan

A bbreviations: NID D M, Non-insulin-dependent diabetes mellitus; ID D M , insulin-dependent diabetes mellitus; Fbg, fibrinogen; prothrombin $\mathrm{F} 1+2$, prothrombin fragment $1+2 ; \mathrm{FM}$, fibrin monomer; PC, protein C antigen; PCA , protein C activity; total PS, total protein $S$ antigen; free PS, free protein $S$ antigen; ST M, soluble thrombomodulin; SE -S, soluble E-selectin; A PC$\mathrm{PCl}$ complex, activated protein $\mathrm{C}$-protein $\mathrm{C}$ inhibitor complex; TA R, thrombomodulin-induced anticoagulant activity rate; BSA, bovine serum albumin.
A Iteration of the clotting system in diabetic patients is presently the focus of increasing interest due to its potential role in the pathogenesis of large and smallvessel disease in diabetes mellitus. It is believed that enhanced pro-coagulant activity is linked to the excessive cardiovascular morbidity and mortality among diabetic patients which have not been fully explained by major risk factors such as arterial hypertension, cigarette smoking and hypercholesterolaemia. Perturbance of haemostasis has also been implicated in the development of complications such as nephropathy and retinopathy and in the acceleration of atherogenesis observed in diabetic patients [1, 2]. 
However, the mechanism by which increased activation of the clotting system occurs in diabetes is not clear.

Thrombogenic tendency results from the disruption of the balance between the prethrombotic and antithrombotic factors that control clotting homeostasis; this imbalance may occur due to an ongoing stimulus to thrombogenesis, a defect of the natural anticoagulant or fibrinolytic process. The most important anticoagulant system is the protein $C$ (PC) pathway. PC is a vitamin $\mathrm{K}$-dependent plasma glycoprotein that, after being proteolytically cleaved by thrombin complexed to thrombomodulin (TM) on the endothelial surface, is converted to activated protein $C$ ( $A P C$ ) which is the enzyme effector of the PC anticoagulant system [3]. A PC exerts anticoagulant activity by inactivating factors $\mathrm{Va}$ and VIIIa on the membrane of platelets and endothelial cells, and also by stimulating fibrinolysis in concert with protein $\mathrm{S}$ (PS) [3]. The biological activity of the anticoagulant PC pathway in diabetes remains controversial; although the plasma antigen levels of PC in diabetes have been previously reported, the degree of PC conversion to its active protease is unclear $[4,5]$. A $n$ assay for measuring levels of A PC in complex with its main inhibitor, $\mathrm{PC}$ inhibitor or $\mathrm{PCl}$ (A PC-PCI complex) has been recently developed [6]. Plasma concentration of A PC-PCI complex represents the direct index of in vivo ongoing $P C$ activation [7].

$T M$ is an endothelial cell membrane protein that also has antithrombotic effect [8]. A side from its role in the thrombin-mediated catalytic activation of PC, $T M$ produces additional anticoagulant effects by inhibiting various thrombin-induced thrombogenic activities such as the proteolysis of fibrinogen, activation of factors $V$ and X III, inactivation of PS and inhibition of platelet aggregation [8]. TM also accelerates the inhibition of thrombin by antithrombin III [9] and $\mathrm{PCI}[10]$. These anticoagulant activities of TM are believed to be impaired in diabetic patients as a result of endothelial injury induced proteolytic cleavage of the membrane-bound TM. H owever, the reactivity of the foregoing plasma components in diabetic patients to the anticoagulant effects of TM is unclear; to clarify this point, in the current study, we evaluated the response against exogenous TM in plasma of diabetic patients.

The present study aimed to assess: 1) the degree of $P C$ activation as measured by the plasma levels of A PC-PCI complex; and 2) the anticoagulant response to exogenous TM in patients with non-insulin-dependent diabetes mellitus (NID D M).

\section{Subjects and methods}

Reagents. The snake venom, reptilase $(200 \mathrm{U} / \mathrm{ml})$, was purchased from Pentafarm A G (Basel, Switzerland) and rabbit brain thromboplastin was from Dade Co., (Miami, Fla.,
USA ). B ovine serum al bumin (BSA) was obtained from Sigma Chemical (St. Louis, Mo., USA) and thrombin chromogenic substrate, S-2238, was from Chromogenix A B, (M ölndal, Sweden). Human prothrombin was purified from plasma as described previously [11], and recombinant human TM prepared as described previously [12]. A nti-PC and anti-PCI antibodies were prepared following previous methods [13, 14]. Streptavidin-peroxidase conjugate was from A mersham International (A msersham, Bucks., UK ). Tetramethylbenzidine peroxidase substrate was from K irkegaard and Perry Laboratories (Bethesda, M d., USA ). A II other chemicals and reagents used in this study were of the best quality commercially available.

Subjects. This study comprised 61 patients ( 34 men, 27 women) with NIDDM selected according to the $N$ ational Diabetes $D$ ata Group Criteria from our outpatient clinic [15]. The age (mean \pm SE M ) of the patients was $58.0 \pm 1.3$ years, ranging between 35 and 77 years. The mean $( \pm$ SE M ) duration of diabetes was $9.8 \pm 1.0$ (range $1-31$ years). Subjects with clinical or laboratory signs of liver dysfunction, malignancy or a history of coagulation disorder were excluded from the study. Fundi of patients were examined by an ophthamologist, who found that there were 33 patients with retinopathy and 12 with neuropathy. Thirty-four cases were being treated with diet alone and 27 with oral hypoglycaemic agents. Informed consent was obtained from all subjects. The study was approved by our institution's review board for human experiments and was carried out following the principles of the $\mathrm{H}$ elsinki Declaration. Thirty-one healthy non-obese and non-diabetic subjects matched for sex (17 men, 14 women) and age (57.1 \pm 3.0 years) served as control subjects. N one of the control subjects had a history of arterial hypertension, cardiopathy, thrombotic or liver disease. D iabetic patients were divided into two groups according to the albumin creatinine index, calculated as urinary albumin concentration/urinary creatinine concentration [16]. The albumin creatinine index correlates significantly with the urinary albumin excretion over a period of $24 \mathrm{~h} \mathrm{[17].} \mathrm{G} \mathrm{roup} \mathrm{I}$ consisted of 39 patients with a normal albumin creatinine index (normoalbuminuria) of less than $30 \mathrm{mg} / \mathrm{g}$ creatinine. G roup II consisted of 22 patients with an albumin creatinine index in the range of $30-300 \mathrm{mg} / \mathrm{g}$ creatinine (microalbuminuria).

$\mathrm{L}$ aboratory measurements. For measurement of clotting parameters and soluble $E$-selectin ( $S E-S$ ), blood samples were taken from an antecubital vein with plastic syringes and collected in polystyrene tubes containing 3.8\% (weight/volume) trisodium citrate $(1 \mathrm{ml}$ anti $\approx$ coagulant $/ 9 \mathrm{ml}$ blood). Blood was then centrifuged at $1200 \times \mathrm{g}$ for $20 \mathrm{~min}$ at $4^{\circ} \mathrm{C}$. Plasma was collected and stored in small aliquots at $-80^{\circ} \mathrm{C}$ until use. Plasma levels of fibrin monomer (FM) and prothrombin fragment $1+2$ (prothrombin $F 1+2$ ) were measured using the $E n$ zymun-Test (B oehringer $M$ annheim, Mannheim, Germany) and Enzygnost F1+2 (Behringwerke A G, Marburg, Germany) immunoassay kits, respectively, following the manufacturer's instructions [18]. The intra-assay and inter-assay precisions of the $\mathrm{FM}$ assay were 4 and $6 \%$, and of the prothrombin $\mathrm{F} 1+2$ assay were 4 and $7 \%$, respectively. The plasma concentration of fibrinogen (intra-assay and inter-assay variations $<10 \%$ ) was measured as previously described [7]. Endothelial cell injury was evaluated by determining the plasma levels of soluble TM ( STM) and soluble E-selectin (sE -S) using commercially available immunoassay kits for STM (Fuji Chemical Co., Takaoka, Japan) and for SE -S (R\&D systems, $M$ inneapolis, Minn., USA ) following the manufacturer's instructions $[19,20]$. The intra-assay and inter-assay precisions were, respectively, 4.5 and $5.2 \%$ for STM and 4.7 and $5.6 \%$ 
for SE -S. Plasma levels of PC antigen were measured by a solid-phase immunoassay using a human polyclonal anti-PC and biotin-labelled monoclonal anti-PC antibodies following previously described methods [7]. The intra-assay and the inter-assay coefficients of variation for PC antigen were 5 and $6 \%$, respectively. PC activity was determined by an amidolytic assay, using B erichrom-Protein C (Berhringwerke A G, Marburg, G ermany). Plasma antigen levels of total PS and free PS were determined as described $[7,21]$. The intra-assay and the interassay variations were less than $10 \%$ for the PC activity, total and free PS assays.

A PC-PCI complex, a marker of ongoing PC activation, was measured in plasma by an enzyme-linked immunoassay as described [7]. B riefly, monoclonal anti-PCl antibody $(3 \mu \mathrm{g} / \mathrm{ml})$ was coated on microtitre plates by overnight incubation. B lood samples were prepared as follows: citrated plasma was treated with barium chloride (final $10 \mathrm{mmol} / \mathrm{l}$ ) and centrifuged at 15 $000 \mathrm{rev} / \mathrm{min}$ for $5 \mathrm{~min}$. The precipitate dissolved in washing buffer $(50 \mathrm{mmol} / \mathrm{l}$ Tris- $\mathrm{HCl}, \mathrm{pH} \quad 7.5,200 \mathrm{mmol} / \mathrm{l} \mathrm{NaCl}$, $0.5 \mathrm{mmol} / / \mathrm{EDTA}, 0.1 \%$ Tween 20 and $0.5 \%$ BSA ) was then incubated overnight in anti-PCI-antibody-coated microtitre plate after appropriate washing and blocking of non-specific bindings. A fter washing, peroxidase-conjugated monoclonal anti-PC antibody $(0.5 \mu \mathrm{g} / \mathrm{ml})$ was added to each microtitre well and incubated for $5 \mathrm{~h}$. A fter washing, peroxidase substrate was added to each well and absorbance was measured at 450 $\mathrm{nm}$. The inter-assay and the intra-assay coefficients of variability were 5 and $7 \%$, respectively.

The TM -induced anticoagulant activity rate (TA R ) was determined by a modified method as previously described [22]. B riefly, $5 \mu$ l of recombinant human TM (final $100 \mathrm{ng} / \mathrm{ml}$ ) or buffer $(25 \mathrm{mmol} / \mathrm{l}$ Tris-HCl, pH 7.4) was added to $50 \mu \mathrm{l}$ of defibrinated plasma and incubated at $37^{\circ} \mathrm{C}$ for $1 \mathrm{~min}$. Thrombin formation was triggered by addition of rabbit brain thromboplastin (1:50 dilution) to plasma treated with TM or buffer alone followed by incubation at $37^{\circ} \mathrm{C}$ for $10 \mathrm{~min}$. The amount of thrombin generation was detected by adding a specific thrombin substrate, S-2238 (final concentration, $1 \mathrm{mmol} / \mathrm{l}$ ). A bsorbance was then measured at $405 \mathrm{~nm}$. TA R was calculated as follows:

$\operatorname{TAR}(\%)=\frac{\text { amount of thrombin in TM }- \text { added plasma }}{\text { amount of thrombin in buffer }- \text { added plasma }} \times 100$

The intra-assay and the inter-assay precisions were 4.7 and $5 \%$, respectively.

Fasting plasma glucose concentration was measured by the glucose oxidase method and haemoglobin $A_{1 c}\left(\mathrm{HbA}_{1 c}\right)$ was determined by H PLC [23]. Serum and urinary creatinine were measured by the Jaffe reaction [24]. Serum cholesterol and triglycerides were determined by enzymatic techniques.

\section{Statistical analysis}

$D$ ata are expressed as the mean \pm SE M unless otherwise specified. The difference between the mean of two variables was calculated by unpaired Student's t-test or Mann-Whitney U test as appropriate. Kruskal-Wallis analysis of variance with B onferroni correction was employed for calculating the difference among the means of three or more variables. Correlations were calculated by multivariate analysis [25]. A software package for Macintosh (Statview 4.11, A bacus Concepts Inc., B erkeley, Calif., U SA ) was employed for the statistical analyses. A p less than 0.05 was considered as statistically significant.
Table 1. Clinical profile and laboratory data of diabetic patients

\begin{tabular}{|c|c|c|}
\hline & \multicolumn{2}{|c|}{ Diabetic patients } \\
\hline & $\begin{array}{l}\text { (normo- } \\
\text { al buminuria) }\end{array}$ & $\begin{array}{l}\text { (micro- } \\
\text { albuminuria) }\end{array}$ \\
\hline $\begin{array}{l}\text { Number of patients } \\
\text { (male/female) }\end{array}$ & $39(22 / 17)$ & $22(12 / 11)$ \\
\hline A ge (years) & $58.2 \pm 2.1$ & $59.1 \pm 2.1$ \\
\hline D iabetes duration (years) & $8.2 \pm 1.4$ & $12.2 \pm 1.4^{b}$ \\
\hline Body mass index $\left(\mathrm{kg} / \mathrm{m}^{2}\right)$ & $23.7 \pm 0.6$ & $22.4 \pm 0.9$ \\
\hline $\begin{array}{l}\text { Fasting plasma glucose level } \\
(\mathrm{mmol} / \mathrm{l})\end{array}$ & $9.8 \pm 0.8$ & $11.0 \pm 0.9$ \\
\hline $\mathrm{H}$ aemoglobin $\mathrm{A}_{1 \mathrm{c}}(\%)$ & $8.3 \pm 0.3$ & $9.4 \pm 0.5$ \\
\hline $\begin{array}{l}\text { U rinary albumin concentration } \\
(\mathrm{nmol} / \mathrm{l})\end{array}$ & $1.4 \pm 0.1$ & $29.4 \pm 1.2^{\mathrm{a}}$ \\
\hline $\begin{array}{l}\text { U rinary albumin index } \\
\text { (mg/g creatinine) }\end{array}$ & $13.5 \pm 1.0$ & $231.7 \pm 12.5^{\mathrm{a}}$ \\
\hline Total cholesterol $(\mathrm{mmol} / \mathrm{l})$ & $12.0 \pm 0.4$ & $12.2 \pm 0.6$ \\
\hline Triglycerides $(\mathrm{mmol} / \mathrm{l})$ & $1.8 \pm 0.2$ & $1.7 \pm 0.3$ \\
\hline $\begin{array}{l}\text { Blood pressure }(\mathrm{mm} \mathrm{H}) \\
\text { Systolic } \\
\text { Diastolic }\end{array}$ & $\begin{array}{r}133.2 \pm 5.9 \\
82.9 \pm 4.1\end{array}$ & $\begin{array}{r}139.6 \pm 7.7 \\
83.1 \pm 6.1\end{array}$ \\
\hline Serum creatinine $(\mu \mathrm{mol} / \mathrm{l})$ & $76.7 \pm 2.1$ & $78.7 \pm 6.1$ \\
\hline
\end{tabular}

a $p<0.0001$, compared to Group I; ${ }^{b} p<0.01$, compared to Group I

\section{Results}

The age, sex, BM I, fasting blood glucose levels, serum creatinine, $\mathrm{HbA}_{1}$, total cholesterol and triglycerides were not significantly different between cases with and without microal buminuria (Table 1 ). In addition, no significant differences were observed in the levels of each parameter between patients treated with diet alone, oral hypoglycaemic agent or with a combination of both therapies. A s shown in Table 2, the plasma levels of fibrinogen $(p<0.02)$, prothrombin $F 1+2(p<0.05), F M(p<0.0001)$, sTM $(p<0.005)$, SE -S $(p<0.005), P C$ antigen $(p<0.005), P C$ activity $(p<0.005)$ and total PS antigen $(p<0.02)$ were markedly elevated in all diabetic patients with diabetes as compared to healthy subjects. The plasma concentration of free PS antigen was, however, significantly lower in diabetic patients than in the healthy control subjects $(p<0.005)$. Comparative evaluation of the foregoing parameters between patients with and without nephropathy disclosed significant increase of the plasma concentrations of fibrinogen $(p<0.05)$, prothrombin $F 1+2(p<0.05)$ and sTM $(p<0.03)$ in cases with microalbuminuria as compared to those with normoalbuminuria (Table 2).

The degree of $P C$ activation as measured by the plasma levels of A PC-PCI complex was significantly $(p<0.0001)$ accelerated in all diabetic patients $(7.4 \pm 3.8 \mathrm{pmol} / \mathrm{l})$ as compared to healthy subjects $(3.0 \pm 0.4 \mathrm{pmol} / \mathrm{l})$ (Fig. 1). Comparison of cases with or without nephropathy with the healthy control 
Table 2. Clotting variables and markers of endothelial cell injury in diabetic patients

\begin{tabular}{|c|c|c|c|c|}
\hline & \multirow[t]{2}{*}{ H ealthy subjects } & \multirow{2}{*}{$\begin{array}{l}\text { A II diabetic } \\
\text { patients }\end{array}$} & \multicolumn{2}{|l|}{ D iabetic patients } \\
\hline & & & (normoalbuminuria) & (microalbuminuria) \\
\hline$\overline{\text { Fibrinogen }(\mu \mathrm{mol} / \mathrm{l})}$ & $10.4 \pm 1.1$ & $13.4 \pm 0.6^{c}$ & $12.0 \pm 0.7$ & $14.1 \pm 0.9^{f}$ \\
\hline Fibrin monomer (ng/ml) & $0.3 \pm 0.1$ & $2.1 \pm 0.4^{a}$ & $1.9 \pm 0.4$ & $2.2 \pm 0.8$ \\
\hline Soluble thrombomodulin ( $\mathrm{pmol} / \mathrm{l})$ & $26.4 \pm 1.2$ & $34.8 \pm 2.9^{b}$ & $31.2 \pm 2.8$ & $41.6 \pm 6.1^{d}$ \\
\hline Soluble E-selectin (pmol/l) & $384.2 \pm 29.4$ & $534.2 \pm 31.4^{b}$ & $556.8 \pm 44.6$ & $495.2 \pm 37.0$ \\
\hline Protein $\mathrm{C}$ antigen (\%) & $92.1 \pm 3.9$ & $110.1 \pm 4.2^{b}$ & $109.6 \pm 5.5$ & $110.8 \pm 6.5$ \\
\hline Free protein S antigen (\%) & $116.4 \pm 4.5$ & $102.1 \pm 2.2^{b}$ & $101.2 \pm 2.5$ & $103.7 \pm 4.1$ \\
\hline
\end{tabular}

${ }^{a} p<0.0001 ;{ }^{b} p<0.005 ;{ }^{c} p<0.02$, compared to healthy subjects; ${ }^{d} p<0.03$, compared to normoalbuminuria patients;

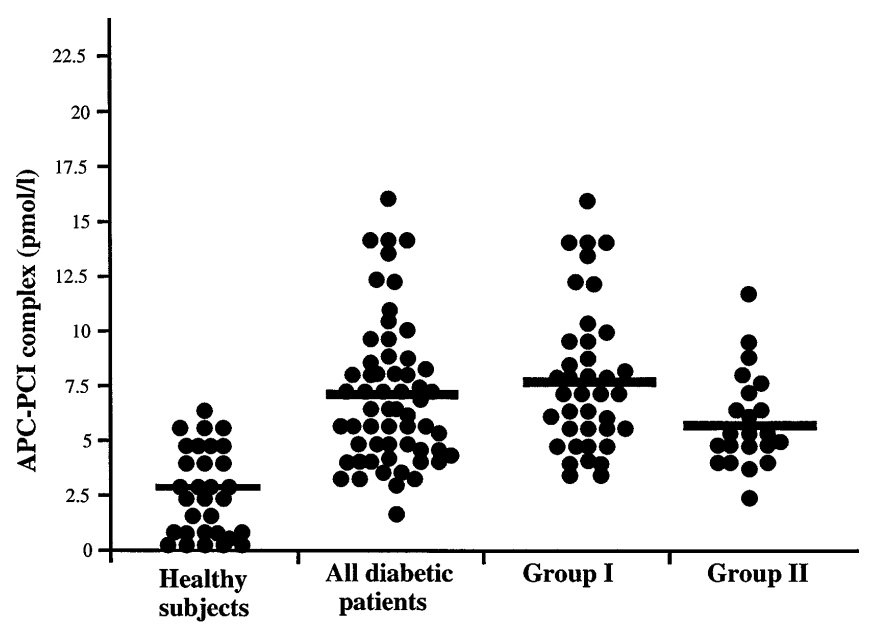

Fig. 1. The plasma levels of A PC-PCI complex were significantly higher $(p<0.0001)$ in all diabetic patients as compared to healthy subjects. Significant elevation in the plasma levels of A PC-PCI complex was observed in either normoalbuminuric (group I; $p<0.0001$ ) or microalbuminuric (group II; $p<0.05)$ patients as compared to the healthy control group. However, subjects from group II presented relatively lower $(p<0.05)$ levels of A PC -PCI complex than those of group I. Bars indicate the mean values

group showed a significant increase of the plasma levels of $\mathrm{APC}-\mathrm{PCl}$ complex in patients presenting normoalbuminuria $(8.6 \pm 0.7 \mathrm{pmol} / \mathrm{l} ; \mathrm{p}<0.0001)$ or microalbuminuria $(5.5 \pm 0.6 \mathrm{pmol} / \mathrm{l} ; \mathrm{p}<0.05) \mathrm{com}$ pared to healthy subjects, suggesting that in either normoalbuminuric (group I) or microalbuminuric (group II) patients there is a significant enhanced PC activation. H owever, comparing patients of group I with those of group II, $(p<0.05)$ the plasma levels of A PC-PCl complex were relatively lower in subjects with nephropathy than in those without this complication (Fig. 1). The TM anticoagulant activity indicated by TA $R$ was significantly $(p=0.005)$ lower in all cases with diabetic subjects $(23.4 \pm 2.6 \%)$ than in healthy subjects $(35.3 \pm 3 \%$ ) (Fig. 2 ). The mean values of TA $R$ decreased significantly in group II patients $(16.5 \pm 2.9 \% ; p<0.0001)$ but weakly in those e $p<0.05$, compared to healthy subjects; ${ }^{f} p<0.05$, compared to normoalbuminuria patients.

$D$ ata are mean \pm SEM

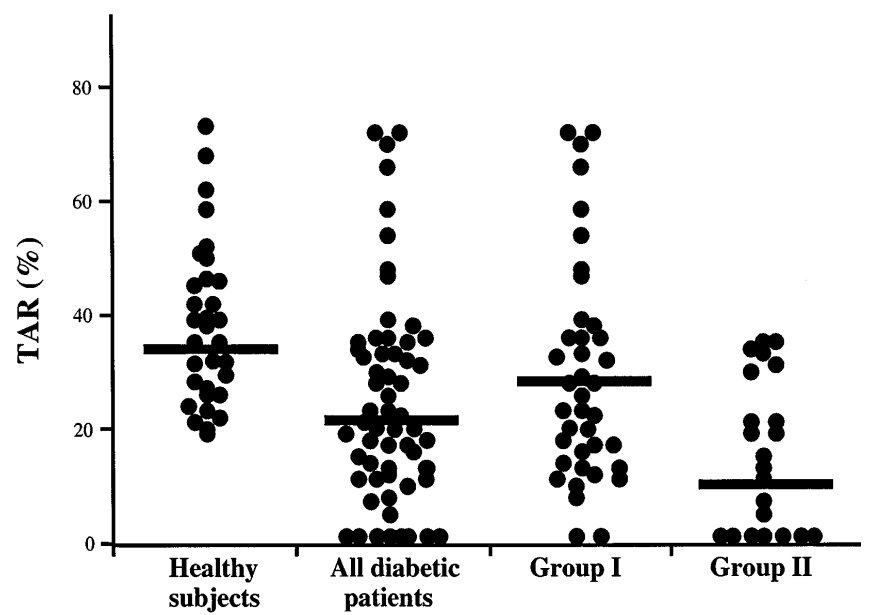

Fig. 2. The anticoagulant response to exogenous TM (TA R) was significantly lower $(p=0.005)$ in all diabetic patients as compared to healthy subjects. Patients with microalbuminuria (group II) showed significantly lower $(p<0.0001)$ values of TAR as compared to healthy control subjects. Comparative evaluation between the normoalbuminuric (group I) and microalbuminuric (group II) patients, disclosed lower $(p=0.03$ ) values of TA R in patients of group II than in those of group I. $B$ ars indicate the mean values

of group I $(28.3 \pm 3.8 \% ; p=0.1)$ as compared to healthy subjects. Patients of group II showed significantly lower $(p=0.03)$ values of TAR than those of group I.

M ultivariate correlations of pro-coagulant and anticoagulant parameters with clinical and metabolic markers are shown in Table 3. The plasma concentration of APC-PCI complex correlated significantly with the values of albumin creatinine index in all patients with diabetes. The PC activity correlated significantly with the levels of $\mathrm{Hb}_{1 \mathrm{c}}$, total cholesterol, triglycerides and serum creatinine as shown in Table 3. The plasma levels of A PC-PCI complex or the values of TAR did not correlate with any glycaemic control parameter. Plasma A PC-PCI complex levels correlated significantly $(r=0.5, p<0.01)$ with the antigen concentration of $P C$, whereas the TAR values 
Table 3. Correlation coefficients of procoagulant and anticoagulant markers with different clinical and laboratory parameters in all diabetic patients

\begin{tabular}{|c|c|c|c|c|c|c|c|c|c|}
\hline & $\mathrm{Fbg}$ & $\mathrm{F} 1+2$ & FM & PC & PCA & Total PS & Free PS & $\mathrm{APC}-\mathrm{PCl}$ & TAR \\
\hline A ge & +0.3 & +0.1 & $+0.4^{a}$ & +0.2 & -0.1 & +0.1 & -0.1 & +0.1 & -0.2 \\
\hline D iabetes duration & $+0.5^{\mathrm{b}}$ & +0.2 & +0.2 & +0.1 & -0.2 & +0.1 & +0.1 & -0.1 & -0.1 \\
\hline Fasting plasma glucose & +0.2 & -0.1 & +0.1 & +0.1 & +0.1 & -0.2 & -0.1 & +0.1 & +0.1 \\
\hline H aemoglobin $A_{1 c}$ & $+0.3^{c}$ & -0.2 & -0.1 & +0.2 & $+0.4^{b}$ & +0.2 & +0.1 & +0.1 & +0.2 \\
\hline U rinary albumin concentration & +0.3 & $-0.3^{c}$ & $-0.3^{c}$ & +0.2 & -0.1 & +0.2 & +0.1 & $-0.3^{c}$ & $-0.3^{c}$ \\
\hline U rinary albumin index & $+0.4^{c}$ & -0.3 & +0.1 & +0.1 & -0.1 & -0.1 & +0.1 & $-0.4^{c}$ & -0.1 \\
\hline Total cholesterol & -0.2 & -0.1 & -0.1 & +0.1 & $+0.5^{\mathrm{a}}$ & +0.1 & +0.2 & +0.1 & -0.1 \\
\hline Triglycerides & $-0.4^{b}$ & -0.1 & -0.1 & +0.2 & $+0.4^{b}$ & +0.2 & -0.1 & +0.1 & -0.1 \\
\hline Serum creatinine & +0.1 & +0.2 & -0.2 & -0.2 & $-0.3^{c}$ & +0.1 & -0.1 & -0.1 & -0.1 \\
\hline
\end{tabular}

a $p<0.003 ;{ }^{b} p<0.02 ;{ }^{c} p<0.05$

Fbg, Fibrinogen; Prothrombin F1+2, prothrombin fragment 1+2; FM, fibrin monomer; PC, protein C antigen; PCA, protein $C$ activity; Total PS, total protein $S$ antigen; Free $P S$, free

protein $\mathrm{S}$ antigen; A PC-PCI, activated protein C-protein $\mathrm{C}$ inhibitor complex; TAR, thrombomodulin-induced anticoagulant activity rate

showed a significant inverse correlation $(r=-0.3$; $\mathrm{p}<0.05)$ with plasma FM levels.

\section{Discussion}

The current study showed that the hyper-coagulable state in NIDDM is associated with an increased activation of $P C$ as expressed by the high plasma levels of A PC-PCI complex. The anticoagulant effect of exogenous TM (TA R ) against the thrombin generation of plasma of diabetic patients was found to be reduced in relation to that of healthy subjects. In addition, a poor anticoagulant response as judged by the decreased formation of A PC-PCI complex and low values of TA $R$ were observed in cases presenting microalbuminuria.

Enhanced activation of the clotting system has been previously reported in patients with insulin-dependent diabetes (IDD M ) or NID D M [4]. High plasma concentrations of $F M$, prothrombin $F 1+2$ and fibrinogen found in our NIDDM patients provide confirmatory evidence of these previous reports [26, 27]. This activation of blood coagulation has been recently implicated as an important contributing factor for the occurrence of vascular complications in diabetes [28]. In large epidemiological studies the pro-coagulant factors, fibrinogen and factor V II, have been described to be independent predictors of cardiovascular events in diabetic and non-diabetic subjects, and the detection of microalbuminuria, another wellknown independent indicator of much greater risk of premature death from cardiovascular complications, has been demonstrated to correlate significantly with various haemostatic variables [4, 29, 30]. A ccordingly, in the present study, the plasma levels of fibrinogen and prothrombin $\mathrm{F} 1+2$ were also found to be significantly higher in diabetic patients with microalbuminuria than in those with normoalbuminuria.

The pathogenic mechanism of the clotting activation in diabetes is not completely clear. Perturbance of components of the anticoagulant system associated with hyper-glycaemia might play an important role. For instance, hyperglycaemia has been shown to induce depressed biological activity of the anticoagulant protein, antithrombin III, in diabetic and non-diabetic subjects [31]. Structural modification dueto non-enzymatic glycation was suggested as the causative factor of this antithrombin III dysfunction [32]. A bnormalities of the anticoagulant PC pathway may also cause hypercoagulability in diabetic patients. The plasma antigen levels of PC and of its cofactor PS were found to be either decreased or increased in various reports depending on the type of diabetes. While reduced plasma levels of PC antigen have been described in IDDM patients, they were found to be elevated in those with NID D M [4,33]. Increased plasma levels of PC antigen were also observed in our NIDDM patients confirming these previous observations. Concerning the functional activity of $P C$, though enhanced anticoagulant response to A PC has been described in IDDM, the degree of PC activation in NIDDM patients remains unclear [34]. To clarify the grade of activity of the anticoagulant PC system in NIDDM, we measured the plasma levels of A PC-PCI complex, a direct index of ongoing $P C$ conversion to its active enzyme A PC. Our data showed for the first time that there is a significant increase in formation of A PC$\mathrm{PCl}$ complex in the circulation of NIDDM patients as compared to healthy subjects, suggesting the existence of an accelerated activation of the anticoagulant PC pathway in this group of diabetic patients. A compensatory response to hyper-coagulable state may explain this increased generation of APC-PCl complex in NID D M . H yperglycaemia has been considered to be the causative factor of the abnormalities of the PC anticoagulant pathway in ID D M , but in our N ID D M patients, no significant correlation was found between pro-coagulant or anticoagulant parameters with markers of glycaemic control [35].

A lthough the A PC-PCI complex levels increased significantly in microalbuminuric patients as 
compared to the healthy control group, they were relatively lower $(p=0.03)$ than those observed in cases with normoal buminuria. The mechanism of this finding cannot be explained by the results of the current study. I t may potentially depend on a lower activation rate of PC due to a severe systemic endothelial cell injury concomitant with the occurrence of microalbuminuria [36]; i.e. aggravation of the systemic microangiopathy may be associated with a progressive diminution of the amount of endothelial surface-bound TM leading to decreased activation of PC. This lesser availability of endothelial membrane-associated TM with subsequent poor PC anticoagulant response may result in further acceleration of the pro-coagulant activity in diabetes. M oreover, decreased activation of PC caused by endothelial cell injury may also diminish the inactivation rate of plasminogen activator inhibitor-1 by A PC, leading to enhanced inhibition of fibrinolytic activity and thus to further thrombogenic tendency [37, 38]. E nhanced thrombogenic tendency as shown by the significant elevation of the plasma concentrations of fibrinogen and prothrombin F $1+2$ in cases with microalbuminuria may be explained by this relatively low-grade PC activation [39].

On the other hand, the endothelial membranebound TM, besides serving as a co-factor for the thrombin-induced activation of PC, may also exert direct thromboprotective effect by inhibiting the proteolytic and thrombogenic actions of thrombin on other clotting proteins and by accelerating the inhibition of thrombin by plasma serine protease inhibitors such as antithrombin III [9] or PCI [10]. The overall TA $R$ was evaluated by using an in vitro assay, and its values were found to be lower in diabetic patients than in normal control subjects. The mechanism of these low TA R values might depend on the inability of TM to inhibit the thrombogenic activity of thrombin or for enhancing the inhibition of thrombin by antithrombin III or $\mathrm{PCl}$, probably due to the occurrence of structural and/or conformational changes of these natural inhibitors in patients with diabetes. This apparent inability of exogenous TM to inhibit thrombin generation by promoting the activity of thrombin inhibitors worsens with the clinical progression of disease, as indicated by the markedly decreased values of TA $R$ in microalbuminuric patients. Further studies are required to clarify the molecular basis of this abnormal TA $R$ in diabetes.

In brief, this investigation showed that the hypercoagulable state in NIDDM is associated with an increased activation of PC but with a low reactivity of plasma of diabetic patients to the anticoagulant effect of TM . In addition, this study suggests that an imbalance between the PC anticoagulant pathway and the coagulation system may be an important causative factor of the enhanced pro-coagulant activity observed in patients presenting microalbuminuria.
A cknowledgements. This work was supported by the R esearch $G$ rant for Cardiovascular D iseases ( $5 A-2)$ and by the G rantin-A id ( 08557064 and 07458151 ) from the M inistry of E ducation of Japan. We gratefully acknowledge the technical assistance of M s. T. H ibi and M S. Y. H asegawa.

\section{References}

1. Fuller JH, Keen H, Jarrett RJ, O mer T et al. (1979) $\mathrm{H}$ aemostatic variables associated with diabetes and its complications. B M J 2: 964-966

2. V ine A K, Samama M M (1993) The role of abnormalities in the anticoagulant and fibrinolytic systems in retinal vascular occlusions. Surv O phthalmol 37: 283-292

3. Suzuki K (1995) Protein C. In: H igh K A , R oberts HR (eds) $M$ olecular basis of thrombosis and hemostasis. D ekker, N ew York, pp 393-424

4. K nöbl P, Schernthaner G, Schnack C et al. (1993) Thrombogenic factors are related to urinary albumin excretion rate in type 1 (insulin-dependent) and type 2 (non-insulindependent) diabetic patients. D iabetologia 36: 1045-1050

5. L ee $P$, J enkins A , B ourke $C$ et al. (1993) Prothrombotic and antithrombotic factors are elevated in patients with type I diabetes complicated by microalbuminuria. Diabet Med 10: $122-128$

6. E spana F, G riffin J H (1989) D etermination of functional and antigenic protein $C$ inhibitor and its complexes with activated protein C in plasma by ELISA s. Thromb Res 55: 671-682

7. M inamikawa K, Wada H, Wakita $Y$ et al. (1994) Increased activated protein $\mathrm{C}$-protein $\mathrm{C}$ inhibitor complex levels in patients with pulmonary embolism. Thromb Haemost 71: 192-194

8. E smon CT (1987) The regulations of natural anticoagulant pathways. Science 235: 1348-1351

9. B ourin M C, L indhal U (1993) G lycosaminoglycans and the regulation of blood coagulation. B iochem J 289: 313-330

10. R ezale A R , Cooper ST, Church FC, E smon CT (1995) Protein $C$ inhibitor is a potent inhibitor of the thrombinthrombomodulin complex.J B iol Chem 270: 25336-25339

11. M iletich J P, B roze G J J r, M ajerus PW (1980) The synthesis of sulfated dextran beads for isolation of human plasma coagulation factors II, IX, and X. A nal Biochem 105: 304-310

12. Suzuki K, Hayashi T, Nishioka J (1989) A domain composed of epidermal growth factor-like structures of human thrombomodulin is essential for thrombin binding and for protein C activation. J Biol Chem 264: 4872-4875

13. Suzuki K, Matsuda Y, Kusumoto $\mathrm{H}$ et al. (1984) Monoclonal antibodies to human protein $C$ : effects on the biological activity of activated protein $\mathrm{C}$ and the thrombin-catalyzed activation of protein C. J B iochem (Tokyo) 97: 127138

14. Suzuki K, D eyashiki Y, N ishioka J et al. (1987) Characterization of a CDNA for human protein $C$ inhibitor: a new member of the plasma serine protease inhibitor superfamily. J Biol Chem 262: 611-616

15. National D iabetes Data Group (1979) Classification and diagnosis of diabetes mellitus and other categories of glucose intolerance. D iabetes 28: 1039-57

16. Shaw A B, R isdon F, L ewis-J ackson J D (1983) Protein creatinine index A lbustix in assessment of proteinuria. BMJ 287: 929-932

17. Cowell CT, R ogers S, Silink M (1986) First morning albumin concentration is a good predictor of 24-hour urinary 
albumin excretion in children with type 1 (insulin-dependent) diabetes. $D$ iabetologia 29: 97-99

18. Lill H, Spannagl M, Trauner A et al. (1993) A new immunoassay for soluble fibrin enables a more sensitive detection of the activation state of blood coagulation in vivo. Blood Coag Fibrinol 4: 97-102

19. I washima Y, Sato T, Watanabe K et al. (1990) Elevation of plasma thrombomodulin level in diabetic patients with early diabetic nephropathy. Diabetes 39: 983-988

20. Carson CW, B eall LD, H under G G, Johnson CM, N ewman W (1993) Serum Elam-1 is increased in vasculitis, scleroderma, and systemic lupus erythematosus. J R heumatol 20: 809-814

21. A miral J, G rosley B, B oyer-N eumann C et al. (1994) New direct assay of free protein $S$ antigen using two distinct monoclonal antibodies specific for the free form. Blood Coag Fibrinol 5: 179-186

22. Duchemin J, Pittet JI, Tartary M et al. (1994) A new assay based on thrombin generation inhibition to detect both protein $\mathrm{C}$ and Protein $\mathrm{S}$ deficiencies in plasma. Thromb H aemost 71: 331-338

23. Cole R A, Soeldner J S, D unn PL, B unn HF (1978) A rapid method for the determination of glycosylated haemoglobins using high liquid chromatography. Metabolism 27: 289: 301

24. H usdan H, R apaport A (1968) Estimation of creatinine by the Jaffe reaction. Clin Chem 14: 222-238

25. A rmitage P, B erry G (1994) Distribution-free methods. In: A rmitage $P, B$ erry $G$ (eds) Statistical methods in medical research.B lackwell, L ondon, pp 448-468

26. Ceriello A, Taboga C, Giacomello R et al. (1994) Fibrinogen plasma levels as a marker of thrombin activation in diabetes. Diabetes 43: 430-432

27. Ceriello A, G iacomello R, Colatutto A , Taboya C, G onano $F$ (1992) Increased prothrombin fragment $1+2$ in type I diabetes mellitus. $\mathrm{H}$ aemostasis 22: $50-51$

28. Jones R L, Petersen CM (1981) The fluid phase of coagulation and the accelerated atherosclerosis of diabetes mellitus. D iabetes 30: [Suppl 2] 33-38
29. Wilhelmsen L, Svardsudd K, Korsan-B engtsen K , L arsson B, Welin L, Tibblin G (1984) Fibrinogen as a risk factor for stroke and myocardial infarction. New Engl J Med 311: 501-505

30. Stehouver CDA, Nautta JJP, Z eldenrust GC, H ackeng W H L, D onker A J M , O ttolancer G J H (1992) U rinary albumin excretion, cardiovascular disease, and endothelial dysfunction in non-insulin-dependent diabetes mellitus. L ancet 340: 319-323

31. Ceriello A (1993) Coagulation activation in diabetes mellitus: the role of hyperglycaemia and therapeutic prospects. Diabetologia 36: 1119-1125

32. Ceriello A, G iugliano D, Q uatraro A et al. (1987) Induced hyperglycaemia alters antithrombin III activity but not its plasma concentration in healthy normal subjects. D iabetes 36: 320-323

33. Vukovich TC, Schernthaner G (1986) D ecreased protein C levels in patients with insulin- dependent type I diabetes mellitus. D iabetes 35: 617-619

34. K rugluger W, Kopp H P, Schernthaner $G$, and $H$ opmeier $P$ (1995) E nhanced anticoagulant response to activated protein C patients with ID D M . D iabetes 44: 1033-1037

35. Ceriello A, Q uatraro A, R usso PD et al. (1990) Protein C deficiency in insulin-dependent diabetes: a hyperglycaemia-related phenomenon. Thromb $\mathrm{H}$ aemost 64: 104-107

36. D eckert $T$, Feldt-R amussen $B$, B orch-J onsen $K$, J ensen $T$, Kofoed-E nevoldsen A (1989) A lbuminuria reflects widespread vascular damage. The Steno hypothesis. D iabetologia 32: 219-226

37. Sakata Y, L oskutoh D J, G ladson CL (1986) M echanism of protein $\mathrm{C}$-dependent clot lysis: role of plasminogen activator inhibitor. Blood 68: 1218-1224

38. Gruden G, Cavallo-Perin P, Bazzan M, Stella S, Vuolo A, Pagano G (1994) PA I-1 and factor VII activity are higher in IDDM patients with microalbuminuria. Diabetes 43 : 426-429

39. Gruden G, B azzan S, Pagano G, Pileri A , Cavallo-Perin P (1993) Microalbuminuria in insulin-dependent diabetes is associated with high levels of prothrombin fragment $1+2$. Thromb R es 72: 541-546 